\title{
Physiotherapy and Mental Health
}

\author{
Michel Probst ${ }^{1}$ \\ https://orcid.org/0000-0002-1389-4862 \\ Departement Rehabilitation Sciences, KU Leuven, Belgium
}

Fecha de recepción: 28 de enero de 2019

Fecha de aprobación: 16 de mayo de 2019

\begin{abstract}
Physiotherapy in mental health care and psychiatry is recognized by the World Confederation for Physical Therapy (WCPT) as a specialty within physiotherapy. Physiotherapy in mental health offers a wide range of interventions in regard of body functions, physical activity, exercises, sensory, body and movement awareness, stress and tense regulation and pain management, based on clinical and scientific evidencebased literature. Additionally, the promotion of a healthy lifestyle and "physio-education" (i.e. the process of providing education and information regarding specific physiotherapy related topics to patients and their family members) should be a responsibility of the physiotherapist. This paper gives a short overview of the interventions in the field of mental health to offer appropriate care to a specific vulnerable but growing group in our society.
\end{abstract}

Keywords: exercise; awareness; health education; healthy lifestyle; psychiatry; physio-education.

\section{Fisioterapia y Salud Mental Resumen}

La fisioterapia en el cuidado de la salud mental y la psiquiatría es reconocida por la Confederación Mundial de Terapia Física (WCPT) como una especialidad dentro de la fisioterapia. La fisioterapia en la salud mental ofrece una amplia gama de intervenciones relacionadas con las funciones corporales, la actividad física, los ejercicios, la sensibilidad sensorial, del cuerpo y el movimiento, el estrés y la regulación de la tensión y el manejo del dolor, según la literatura clínica y científica basada en la evidencia. Además, la promoción de un estilo de vida saludable y la "educación física" (es decir, el proceso de proporcionar educación e información sobre temas específicos relacionados con la fisioterapia a los pacientes y sus familiares) debe ser responsabilidad del fisioterapeuta. Este documento ofrece una breve descripción de las intervenciones en el campo de la salud mental para ofrecer la atención adecuada a un grupo específico vulnerable pero en crecimiento en nuestra sociedad.

Palabras clave: ejercicio; concienciación; educación en salud; estilo de vida saludable; psiquiatría; fisioeducación.

${ }^{1}$ Correo de contacto: Michel.probst@kuleuven.be DOI: 10.30788/RevColReh.v18.n2.2019.396

Esta obra se encuentra bajo licencia internacional CC BY 4.0 Institución editora: Escuela Colombiana de Rehabilitación 


\section{Introduction}

The prevention, treatment and rehabilitation of persons with mental health problems and disorders is a topic of growing interest in our society. The implementation of physiotherapy in mental health care and psychiatry is often overlooked. Therefore, the international organisation of physiotherapy in mental health (IOPTMH) was set up (Probst, 2012; www.iopthmh.org). The purpose was to bring the different existing physiotherapeutic interventions in mental health together and to develop different initiatives (conferences, books, newsletters...) to demonstrate the potential value of physiotherapy in the prevention, treatment and the rehabilitation of persons with mental health problems, mental illness and psychiatric disorders (Probst \& Skjaerven, 2018). The theme "Mental health is all physio's business" of the $7^{\text {th }}$ International conference of physiotherapy in psychiatry and mental health underlined the growing importance of mental health in physiotherapy. This idea was also supported by the WCPT-World Physical Therapy Day 2018 theme: "Physical therapy and mental health" and by the First International Conference of Physiotherapy in Mental Health in the United States of America.

The goal is to present an overview of physiotherapy methods and their applications in the fields of mental health and psychiatry as well as some guidelines to improve the recognition of physiotherapy in the sector of mental health care.

\section{Defining the scope of physiotherapy in mental health and psychiatry:}

Physiotherapy in mental health and psychiatry addresses function, activity and participation using physical activity, exercise, relaxation, movement and body awareness approaches to connect the physical and mental health needs of people. Physiotherapists in mental health and psychiatry use both physical and psychological orientated approaches to achieve personal lifestyle modifications that are relevant and sustainable. These strategies empower individuals towards greater independence and self-management of personal health and wellbeing.

Physiotherapists can be employed to work with people with diagnosed mental health conditions in hospital and/or community based mental health and psychiatric settings. Within these environments, physiotherapy supports people to achieve optimal physical and mental wellbeing which may involve addressing physical issues associated with their illness, side effects of medications or comorbid physical health issues.

Another possibility is that physiotherapists work with people outside of the mental health and psychiatric settings, treating people who have chronic physical conditions such as diabetes, cardiovascular disease, cancer, musculoskeletal disorders and chronic pain disorders. These people may have been diagnosed with comorbid mental health disorders or may have undiagnosed comorbid mental health problems.

The IOPTMH developed a definition that generally describes the field of physiotherapy in mental health that is recognizable among most colleagues across the world.

"Physiotherapy in mental health is a specialty within physiotherapy. It is implemented in different health and mental health settings: psychiatry and psychosomatic medicine. It is person- 
centered and provided for children, adolescents, adults and older people with common (mild, moderate) and severe, acute and chronic mental health problems, in primary and community care, inpatients and outpatients. Physiotherapists in mental health provide health promotion, preventive health care, treatment and rehabilitation for individuals, groups and in group therapeutic settings. They create a therapeutic relationship to provide assessment and services specifically related to the complexity of mental health within a supportive environment applying a model including biological and psycho-social aspects. Physiotherapy in mental health aims to optimize wellbeing and empower the individual by promoting functional movement, movement awareness, physical activity and exercises and bringing physical and mental aspects together. It is based on the available scientific and best clinical evidence. Physiotherapists in mental health contribute to the multidisciplinary team and inter-professional care" (Probst et al., 2016; Probst \& Skjaerven, 2018).

\section{Physiotherapy in mental health care}

Figure 1 illustrates in a clear and detailed way the broad scope of the specialties in physiotherapy in mental health care (Probst, 2017, Probst, 2018).

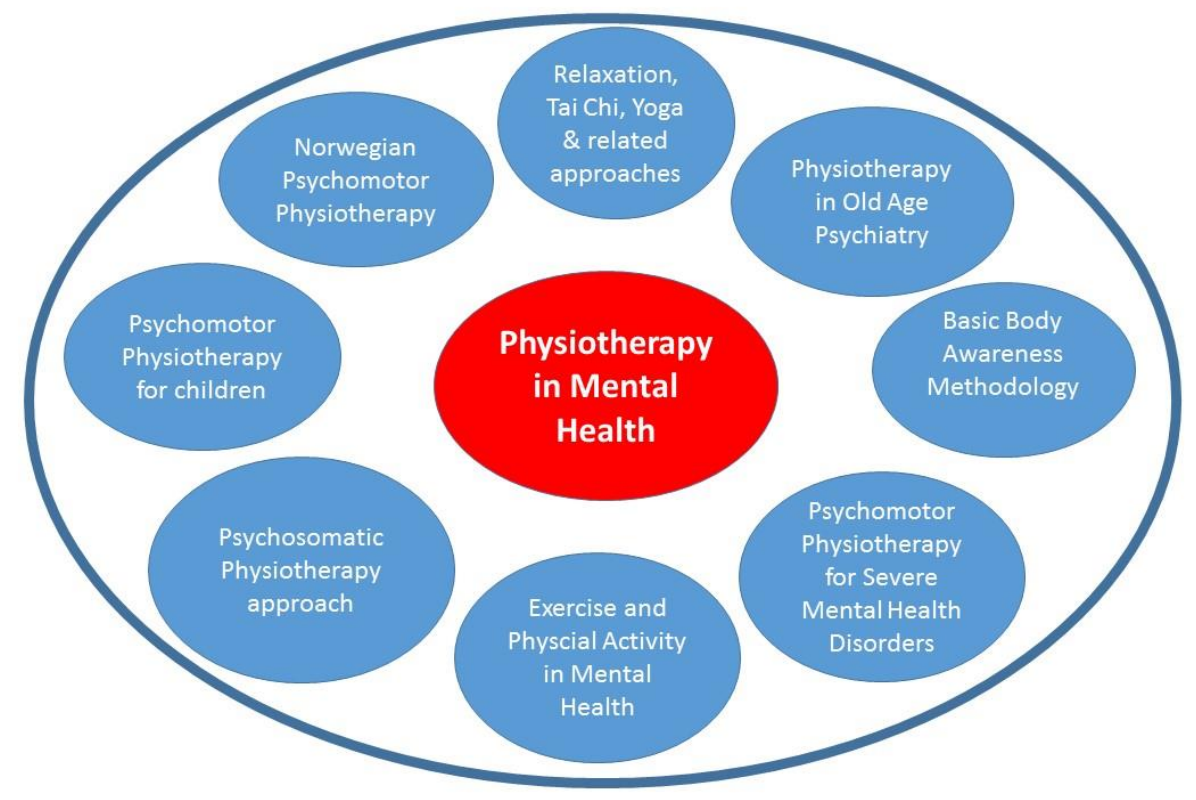

Figure 1: The scope of interventions of Physiotherapy in Mental Health Care (Probst, 2017a)

More detailed the interventions are focused on:

Physical activity, physical fitness and exercise. Physiotherapists are the movement specialists in mental health. Today, there is scientific evidence about the positive vicious circle of physical activity (PA) and Mental Health. Mental symptoms are prevented and reduced by PA and at the same time physical health and quality of life are improved (WHO, 2010; Stubbs \& Rosenbaum, 2018).

Sensory - Body - Movement awareness. Awareness is an important concept in mental health and refers to perception, feelings, recognition or the state of being conscious of the senses, the body, and the movements. Awareness can be defined as an attentive, relaxed and alert presence, not analogous with 
concentration. Awareness encompasses the sensitivity to bodily signals, the ability to recognize subtle body cues and the sense of bodily self, in interaction with the environment (Fogel, 2009, Mehling et al, 2011, Skjaerven et al., 2018). The Basic Body Awareness Methodology (BBAM) (Skjaerven, 2013) and the Norwegian psychomotor therapy (Thornquist \& Bunkan, 1991) were developed from physiotherapy. In other approaches such as Dance Movement Therapy, rhythmical movements, yoga, Tai Chi, Pilates, Mindfulness, Mensendieck, and Feldenkrais an improved body awareness is one of the main goals.

Stress and Tension regulation and the use of relaxation techniques. Persons with mental health problems are more susceptible to stress and tension. Physiotherapists have several ways to regulate tension (Progressive Muscle Relaxation, Autonomous Training and other relaxation approaches). These methods can influence the bodily and mentally tension (Payne, 2005).

Touch, Hands-on or hands-off approach. Body contact, touch and closeness are difficult issues for patients with mental health to cope with. Touching has a therapeutic effect (Calsius et al., 2016, Staub, 2019), however touch and closeness should be used consciously and in a controlled-manner in therapy since they can also have a negative influence (Potz, 2009; Staub, 2019). Physiotherapists are trained in using hands-on and hands-off techniques (i.e. massage) and touch, in complex and sensitive context to support patients (improving feelings of well-being) and to cope with this issues in a safe way.

The Body language and somatic symptom disorders. Somatic symptom disorders and related disorders (A.P.A., 2013) means that a physical condition causes significant distress and or interferes with daily functioning. Mental problems are expressed as physical symptoms, such as pain, weakness, fatigue, nausea and other bodily sensations (= somatization). It is as a form of communication between the conscious and the unconscious mind, through the body. Illness is a person's way of adapting to the environment. Physiotherapists have different strategies (adapted exercise, awareness...) to cope with this disorders.

Pain management. Many patients suffer from conditions with persistent prolonged physiological and emotional pain. Physiotherapists are well placed to treat people with pain in an inter-disciplinary setting by using (a combination of) physical exercise, graded activity, exposure related exercises, movement and body awareness, pain reducing approaches and relaxation training.

Psychologically inspired physiotherapy.To optimize these physiotherapy interventions in mental health the physiotherapist translates ideas from psychology (f.i. self-determination theory, motivational interview, ideas of cognitive behavioural therapy...) into an optimal physiotherapy approach. Physiotherapists are very well positioned to manage and modify a patient's maladaptive thoughts related to the body and exercise (Donaghy, Nicols \& Davidson, 2008; Porter, 2017; Rovner \& Skinta, 2018).

Physio-education. Physio-education refers to the process of providing education and information regarding a specific topic to patients and their family members. Physio-education becomes an essential component of the physiotherapy program in mental health. The goals are to clarify the positive and negative health effects of physical activity and help patients to understand the effects of exercise, stress regulation, awareness and pain management from physiological and psychological points of view, including the risks. With this insightful information, patients are often better able to address the challenges and experience more control and better well-being. 


\section{Conclusion}

Nowadays, physiotherapists are more and more confronted with patients who are suffering from chronic musculoskeletal and mental health problems. Surveys revealed that a great amount of physiotherapists are afraid to treat persons with mental health problems. Following reasons were enumerated: a limited training, a lack of skills on how to address the illness, feelings of uncertainty and unpreparedness towards patients with psychological distress or mental illness and a lack of knowledge about the benefits of physiotherapy for people with mental illness (Probst \& Peuskens, 2010; Yucel \& Acar, 2016; Schwank \& Brunner, 2016; Connaughton \& Gibon, 2016; Stewart, Laasko \& Connaughton, 2016).

Today, the literature (Everett, Donaghy \& Fever, 2003; Probst \& Skjaerven, 2018) offers a lot of scientifically derived knowledge and knowledge gained through years of experience (professional practice) to address complex mental health challenges such as long-lasting musculoskeletal disorders, chronic pain, somatic symptom disorders and divers mental health problems. The "body in movement" is the core business of our expertise and the body and the body in movement are two important issues that are integral to psychopathology.

Therefore, physiotherapy associations and physiotherapy education need to give more attention to the field of mental health in their curriculum. Physiotherapists working in the field of mental health require supplementary knowledge (e.g., psychopathology, psychological frames) and specific (physiotherapeutic) skills and competences (e.g., communication) to assess, treat, support and refer people with mental disorders effectively.

This growing group of vulnerable persons who are more receptive to alternative approaches deserve an appropriated cost-effective and secure health care, based on high quality interventions. These interventions require careful and individually adapted planning according the individual's psychophysical functioning, needs and wishes and sufficient resources to implement the programme.

\section{Author Contributions}

The author has made substantial, direct and intellectual contribution to the work, and approved it for publication.

\section{Conflict of Interest Statement}

The author declare that the research was conducted in the absence of any commercial or financial relationships that could be construed as a potential conflict of interest. 


\section{References}

American Psychiatric Association [APA] (2013). Diagnostic and statistical manual of mental disorders DSM-V (5th ed.). Washington DC: APA Press.

Calsius, J., De Bie, J., Hertogen, R. \& Meesen, R. (2016). Touching the lived body in patients with medically unexplained symptoms. How an integration of hands-on bodywork and body awareness in psychotherapy may help people with alexithymia. Frontiers in Psychology, 253, 1-11. doi: 10.3389/fpsyg.2016.00253

Connaughton, J., \& Gibson, W. (2016). Physiotherapy Students' Attitudes toward Psychiatry and Mental Health: A Cross-Sectional Study. Physiotherapy Canada, 68(2), 172-178. doi:10.3138/ptc.2015-18E

Donaghy, M., Nicol, M. \& Davidson, K.M. (2008) Cognitive Behavioural Interventions in Physiotherapy and Occupational Therapy. London: Butterworth-Heineman.

Everett, T., Donaghy, M. \& Fever, S. (2003) Interventions for mental health: an evidence based approach for physiotherapists and occupational therapists. Edingburgh, Scotland: Butterwood Heinemann.

Fogel, A. (2009). The psychophysiology of self-awareness: rediscovering the lost art of body sense. New York, USA: W.W. Norton.

Mehling, W.E., et al. (2011). Body Awareness: a phenomenological inquiry into the common ground of mind-body therapies. Philos Ethics Humanit Med. 2011;6: 6. doi: 10.1186/1747-5341-6-6.

Mehling, W. E., Wrubel, J., Daubenmier, J. J., Price, C. J., Kerr, C. E., Silow, T., ... Stewart, A. L. (2011). Body Awareness: a phenomenological inquiry into the common ground of mind-body therapies. Philosophy, ethics, and humanities in medicine : PEHM, 6, 6. doi:10.1186/1747-5341-6-6

Payne, R. (2005). Payne's Handbook of Relaxation Techniques. 4th Edition. A Practical Guide for the Health Care Professional. London: Churchill Livingstone.

Porter S. (2017). Psychologically informed physiotherapy. Elsevier: London.

Pötz, H. (2009). Professionelle Distanz nützt Therapeut und Patient. Physiopraxus 7, 52-54. Doi: 10.1055/s-00321308304

Probst, M. \& Peuskens, J. (2010). Attitudes of Flemish physiotherapy students towards mental health and psychiatry. Physiotherapy, 96, 44-51. doi: 10.1016/j.physio.2009.08.006.

Probst, M, (2012) The International Organization of Physical Therapists working in Mental Health (IOPTMH). Mental Health and Physical Activity, 5 (1), 20-21. Doi: 10.1016/j.mhpa.2012.04.003

Probst, M., Skjaerven, L.H., Parker, A., Gyllensten, A.L., IJntema, R. \& Catalán-Matamoros, D. (March, 2016). Do you support this definition of physiotherapy in mental health? In 6th International Conference on Physiotherapy in Psychiatry and Mental Health [Abstract 117], Madrid, España. https://doi.org/10.1016/j.ft.2016.04.002

Probst, M (2017). Physiotherapy in mental health. In: T. Suzuki (Ed), Clinical physical therapy. Zagreb: Intech. InTech, Retrieved from: http://www.intechopen.com/books/

Probst, M. \& Skjaerven L. (2018). Physiotherapy in Mental Health and psychiatry: a scientific and clinical based approach. London: Elsevier.

Probst, M. (2018). Physiotherapy in mental health: an historical overview. Sjukkrabjalfarinn (Icelandic physiotherapy journal), 46(2), 10-12. Retrieved from: https://limo.libis.be/primoexplore/fulldisplay?docid=LIRIAS2338789\&context=L\&vid=Lirias\&search_scope=Lirias\&tab=default_ta b\&lang=en_US\&fromSitemap=1

Rovner, G. \& Skinta, M.D. (2018). Acceptance and commitment therapy in physiotherapy. In: Probst M, Skjaerven L. (Eds). Physiotherapy in Mental Health and psychiatry: a scientific and clinical based approach. (pp. 36-49) London: Elsevier. 
Schwank, A. \& Brunner, E. (2016). Attitudes towards psychiatry of physiotherapy students from Germanspeaking countries: an international comparison. In 6th International Conference on Physiotherapy in Psychiatry and Mental Health [Abstract 91], Madrid, España. https://doi.org/10.1016/j.ft.2016.04.002

Skjaerven, L. (2013). Basic body awareness therapy. Promoting movement quality and health for daily life. Bergen: Hogeskolen.

Skjaerven, L.H., Mattsson, M., Catalan-Matamoros, D., Parker, A., Gard, G., \& Gyllensten, A.L. (2018). Consensus on core phenomena and statements describing Basic Body Awareness Therapy within the movement awareness domain in physiotherapy. Physiotherapy Theory and Practice, 26, 1-14. doi: 10.1080/09593985.2018.1434578.

Staub, C. (2019). Factsheet neurophysiology: physiotherapy and psyche. Retrieved from: www.Physiofuture.ch

Stewart, A., Laasko, L., \& Connaughton, J. (2016). Attitudes of quensland physiotherapists toward psychiatry. In 6th International Conference on Physiotherapy in Psychiatry and Mental Health [Abstract 7], Madrid, España. https://doi.org/10.1016/j.ft.2016.04.002

Stubbs, B. \& Rosenbaum, S. (2018). Exercise based interventions for mental illness. London: Elsevier. Thornquist, E., \& Bunkan, B.H (1991). What is psychomotor therapy? Oslo: Norwegian university press.

World Health Organization (2010). Global strategy on diet, physical activity and health. Geneva, Switzerland: WHO. Retrieved from: www.who.int/dietphysicalactivity/pa/en/index.html

Yucel, H. \& Acar, G. (2016). Levels of empathy among undergraduate physiotherapy students: A cross-sectional study at two universities in Istanbul. Pak J Med Sci. 32(1):85-90. doi: 10.12669/pjms.321.8745.

\section{Notes.}

This article is part of the central conference "Fisioterapia en Psiquiatría y Salud Mental. Pasado, presente y futuro" presented by the author in the Primer Congreso de Fisioterapia en Psiquiatría y Salud Mental del Continente Americano. (Mexico, September 2018)

\section{Author information}

Michel Probst, PhD, PT, is professor at the KU Leuven Department of Rehabilitation Sciences (Belgium). $\mathrm{He}$ is head of the research unit Adapted Physical Activity and Psychomotor Rehabilitation and responsible for the education physiotherapy in mental health. He is founder and president of the IOPTMH (WCPTsubgroup).

Michel.Probst@kuleuven.be

https://orcid.org/0000-0002-1389-4862 